\title{
Whole-fornix endoscopic submucosal dissection for gastric mucosal adenocarcinoma
}



- Fig. 1 A huge superficial elevated lesion was observed in the entire fornix, after marking.

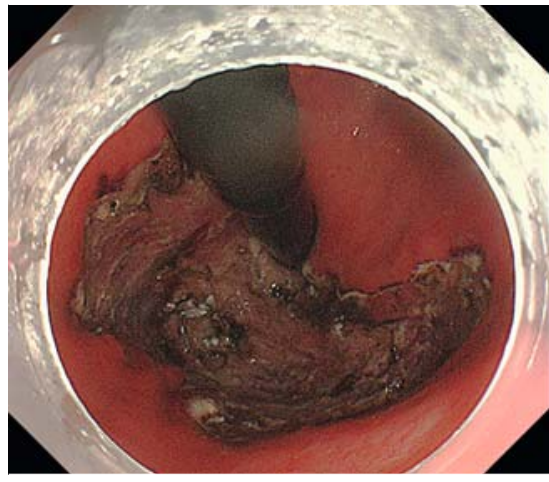

- Fig. 4 Mucosal defect after endoscopic submucosal dissection.

A 69-year-old man with a history of radiation therapy for gastric malignant lymphoma had undergone follow-up esophagogastroduodenoscopy (EGD) at a previous institution, and a superficial elevated lesion was found at the fornix. Examination of a biopsied specimen revealed well-differentiated adenocarcinoma. Endoscopic submucosal dissection (ESD) was attempted, but the procedure was stopped because Mallory-Weiss syndrome occurred in and around the lesion during endoscopic observation immediately before starting ESD. The patient was then referred to our hospital for fur-

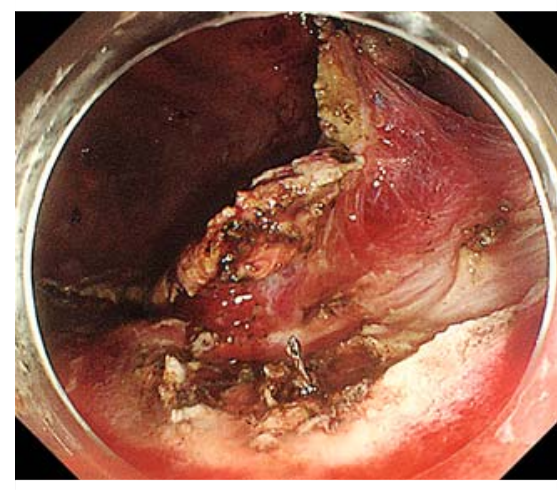

- Fig. 2 The dissecting plane of the submucosal layer was distinctly observed by pulling the clip-and-line system.



> Fig. 5 The lesion was resected en bloc.

ther treatment. EGD at our institution revealed a huge superficial lesion occupying the whole fornix ( $\mathbf{F i g . 1}$ ). As no evidence of invasive cancer was found, we performed endoscopic resection.

A multi-bending two-channel scope (GIF-2TQ260M; Olympus Medical Systems, Tokyo, Japan) was used because this device can closely approach the fornix. We performed traction-assisted ESD using the clip-and-line technique [1-4]. After performing a mucosal incision on the anterior side of the lesion using a FlushKnife BT (DK2618JB15; Fujifilm Medical, Tokyo, Japan) and an

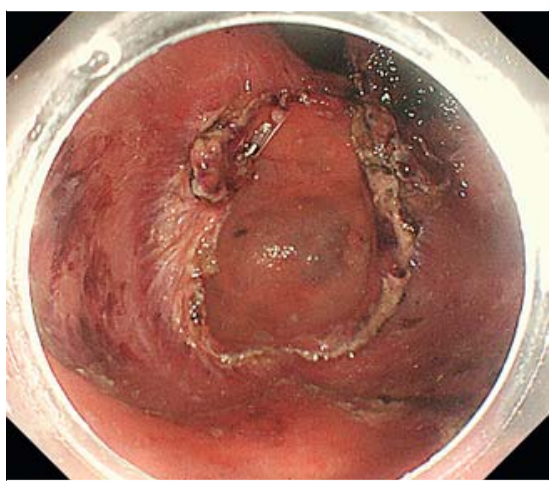

- Fig. 3 The use of multiple clip-and-line procedures facilitated submucosal dissection from both the anterior and posterior sides.

ITknife2 (KD-611L; Olympus Medical Systems), we grasped the anterior side of the specimen with the clip-and-line technique. The dissecting plane of the submucosal layer was distinctly observed by pulling the line ( $\triangleright$ Fig. 2), and submucosal dissection was then easily performed. After creating a circumferential incision, a second clip-and-line procedure was applied to facilitate submucosal dissection of the anterior wall [5] (\$ Fig.3). Perforation occurred during dissection, but the defect was promptly closed by endoscopic clipping. Using a third clip-andline procedure on the greater curvature side of the specimen, the specimen was resected en bloc (> Fig.4, $>$ Fig.5). The pathological diagnosis of the resected specimen was an intramucosal adenocarcinoma with a diameter of $110 \times 48 \mathrm{~mm}$.

Endoscopy_UCTN_Code_CPL_1AH_2AZ

\section{Acknowledgement}

We thank Angela Morben, DVM, ELS, from Edanz Group (https://en-author-services.edanzgroup. com/), for editing a draft of this manuscript. 




Video 1 Whole-fornix endoscopic submucosal dissection for gastric mucosal adenocarcinoma.

\section{Competing interests}

The authors declare that they have no conflict of interest.

The authors

\section{Satoki Shichijo, Yoji Takeuchi, Hiromu}

Fukuda, Akira Maekawa, Takashi Kanesaka, Noriya Uedo, Ryu Ishihara

Department of Gastrointestinal Oncology, Osaka International Cancer Institute, Osaka, Japan

3-1-69 Otemae, Cyuo-ku, Osaka 541-8567, Japan

\section{Fax: +81-6-69814067}

shichijiyou-tky@umin.ac.jp

\section{References}

[3] Shichijo S, Yamasaki Y, Takeuchi Y. Case of colonic adenoma involving a diverticulum resected by a traction-assisted endoscopic submucosal dissection technique. Dig Endosc 2017; 29: 729-730

[4] Shichijo S, Takeuchi Y, Matsuno K et al. Pulley traction-assisted colonic endoscopic submucosal dissection: a retrospective case series. Dig Dis 2019; 37: 473-477

[5] Yamasaki Y, Harada K, Okada H. Tractionassisted endoscopic submucosal dissection for a giant rectal tumor: multiple clip-andthreads technique. Dig Endosc 2018; 30 : 697-699

\section{Bibliography}

DOI https://doi.org/10.1055/a-1085-9472

Published online: 22.1.2020

Endoscopy 2020; 52: E243-E244

(c) Georg Thieme Verlag KG

Stuttgart · New York

ISSN 0013-726X

\section{ENDOSCOPY E-VIDEOS \\ https://eref.thieme.de/e-videos}

[1] Yoshida M, Takizawa K, Suzuki S et al. Conventional versus traction-assisted endoscopic submucosal dissection for gastric neoplasms: a multicenter, randomized controlled trial (with video). Gastrointest Endosc 2018; 87: 1231-1240

[2] Oyama T. Counter traction makes endoscopic submucosal dissection easier. Clin Endosc 2012; 45: 375-378 